\title{
FIRST MOLECULAR DETECTION OF LEISHMANIA INFANTUM IN SERGENTOMYIA MINUTA (DIPTERA, PSYCHODIDAE) IN ALENTEJO, SOUTHERN PORTUGAL
}

Pereira, $\mathrm{S}^{1}$, Pita-Pereira, $\mathrm{D}^{*}{ }^{2}$, Araujo-Pereira, $\mathrm{T}^{2}$, Britto, $\mathrm{C}^{2}$, Costa-Rego, $\mathrm{T}^{2}$, Ferrolho, $\mathrm{J}^{1}$, Vilhena, $\mathrm{M}^{3}$, Rangel, EF, ${ }^{4}$ Vilela, $M L^{4} \mathrm{Afonso}, \mathrm{MO}^{1}$

1Unidade de Ensino e Investigação em Parasitologia Médica (UEI PM), Global Health and Tropical Medicine (GHTM), Instituto de Higiene e Medicina Tropical, Universidade Nova de Lisboa, Portugal 2Laboratório de Biologia Molecular e Doenças Endêmicas, Instituto Oswaldo Cruz, FIOCRUZ, Rio de Janeiro, Brazil '3epartamento de Medicina Veterinária, Universidade de Evora, Portugal ${ }^{4}$ Laboratório Interdisciplinar de Vigilância Entomológic em Diptera e Hemiptera, Instituto Oswaldo Cruz, FIOCRUZ, Rio de Janeiro, Brazil *corresponding author: danypyta@gmail.com

\section{Introduction}

- Five phlebotomine sand species are known in Portugal. Phlebotomus perniciosus and P. ariasi are proven vectors of Leishmania infantum

- Sergentomyia minuta infected with L. major was detected in Algarve, by molecular techniques (Campino et al. 2013)

- There are three known foci of leishmaniasis: Trás-os-Montes and Alto Douro, Lisbon and Algarve regions. However, canine leishmaniasis have been reported in other regions, namely Alentejo (Évora and Beja)

- The aims of this study were: to identify the phlebotomine sand fly species in different biotope types, to determine their relative abundance and the Leishmania infection rate, in Évora and Beja districts

\section{Methods}

- Sand fly captures - May-November 2016, Évora and Beja (Alentejo) (Fig. 1)

- CDC light-traps - domestic and peridomestic biotopes (Fig. 2)
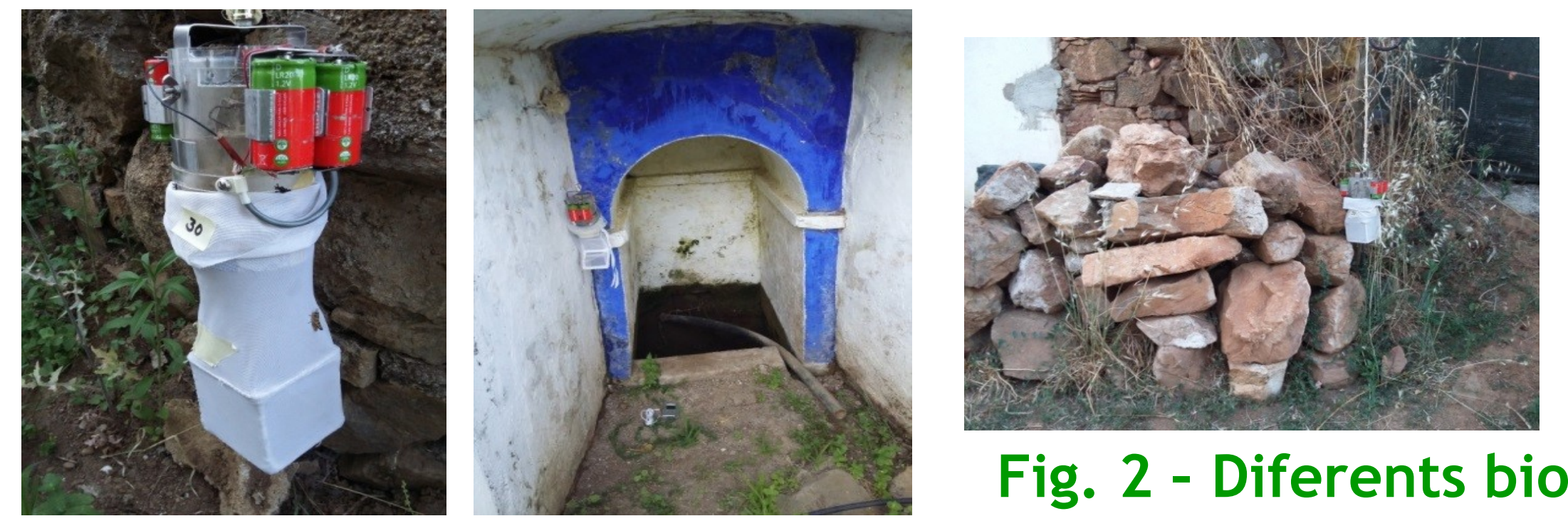

Fig. 2 - Diferents biotopes in Alentejo

- Morphological identification of phlebotomine species by entomological keys

- Leishmania infection by molecular diagnosis in 28 non-blood-fed females wa performed as previously described by Pita-Pereira et al., 2008, wit| modifications. Rigorous procedures were assumed in order to control potentia contamination, e.g. we included negative control groups (male sand flies) in the DNA extraction.

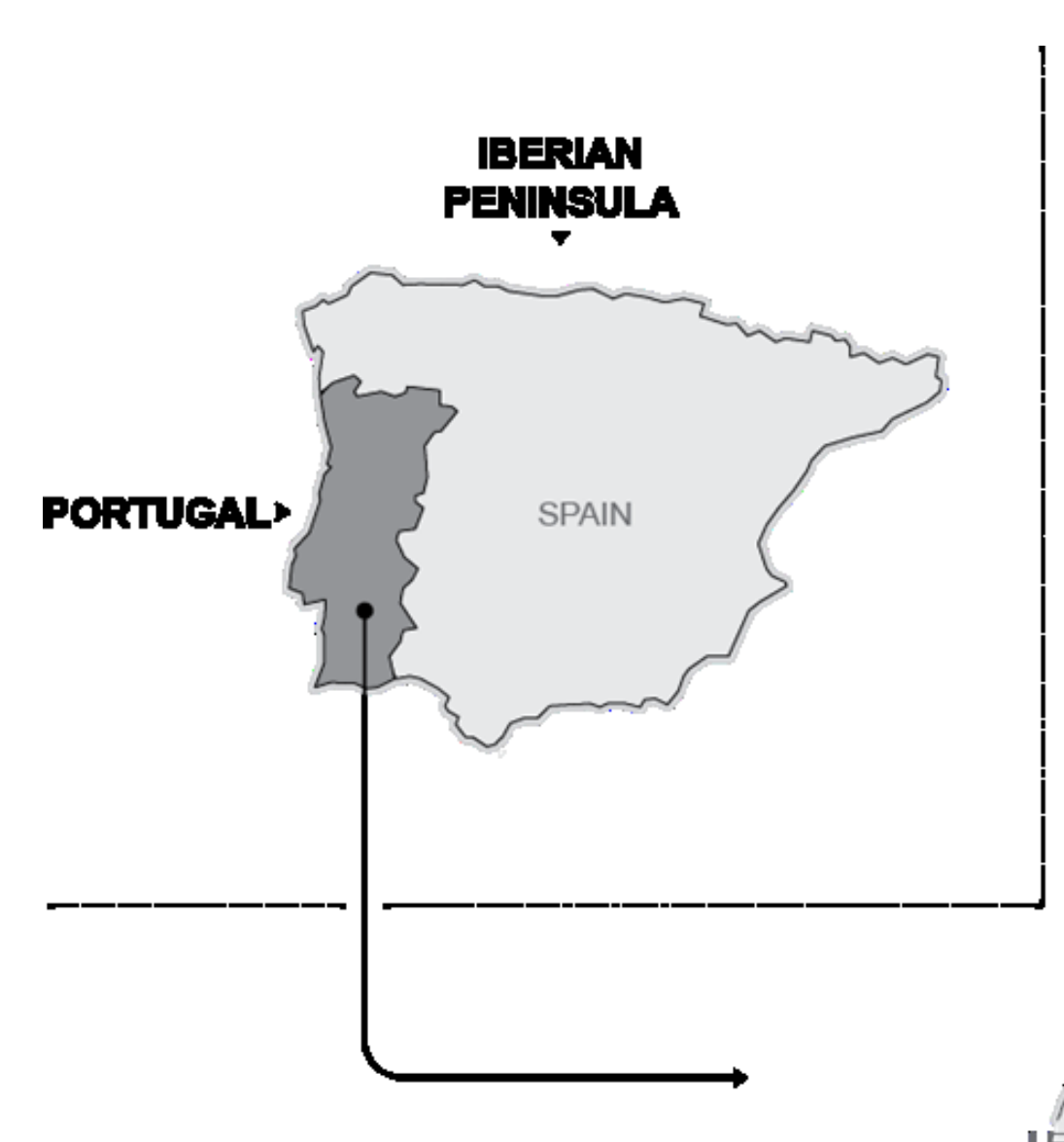

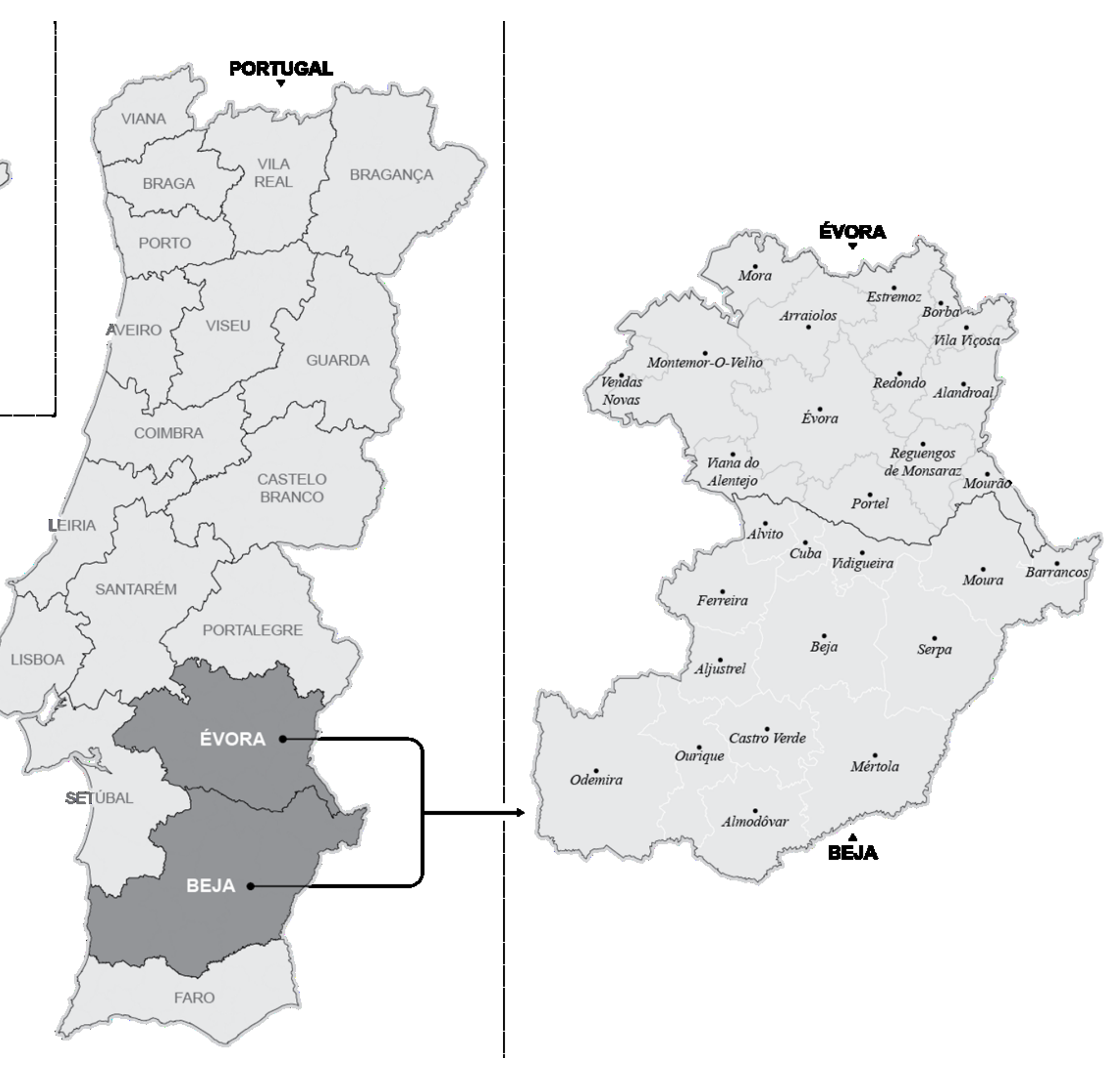

Fig. 1 - Portugal map and are signed the districts and municipalities of Alentejo where the sand fly captures were performed in 2016

\section{Results and Conclusions}

1. 147 sand flies were collected from May to August, 2016: $109 \widehat{\delta}$ and 38 ㅇ

2. 48 CDC light traps were used: $48 \%$ (23/48) positive for the presence of sand flies

3. The Relative abundance of female sand fly species was determined (Fig. 3):

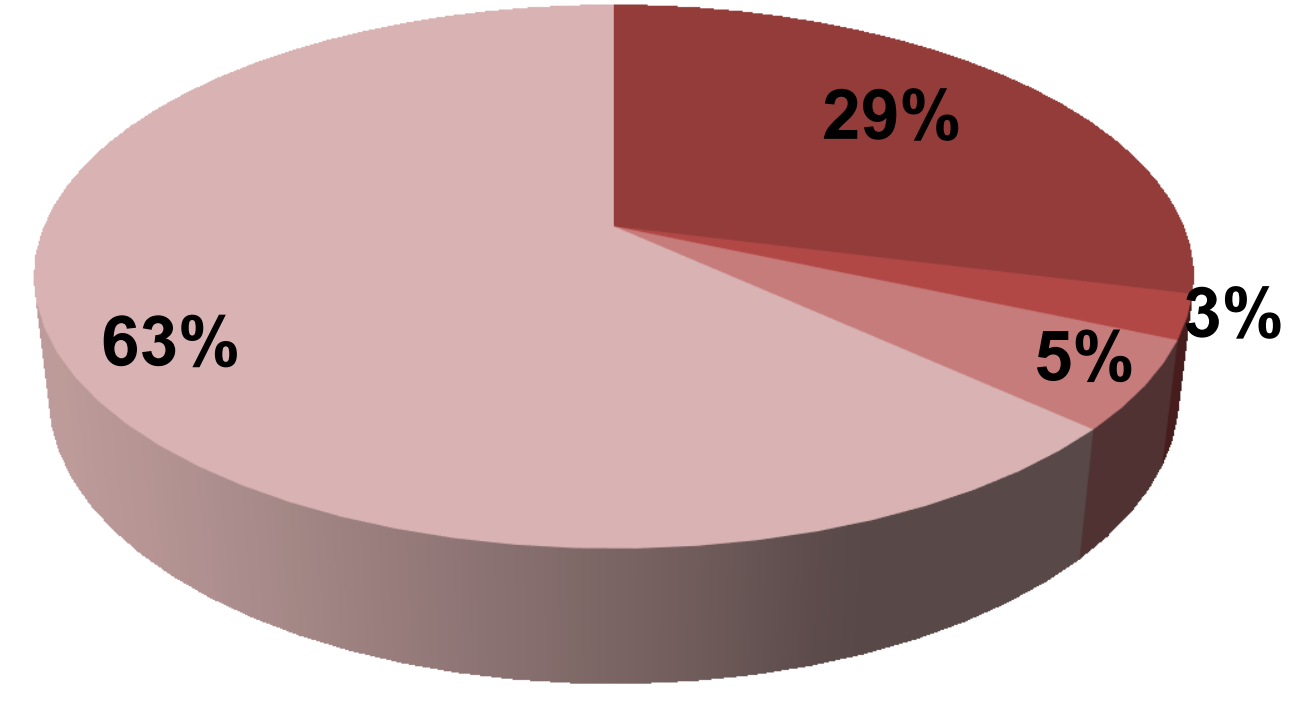

Fig. 3 - Relative abundance of female sand fly species captured in Évora and Beja, 2016

\section{Phlebotomus perniciosus \\ Phlebotomus ariasi \\ - Phlebotomus sergenti \\ Sergentomyia minuta}

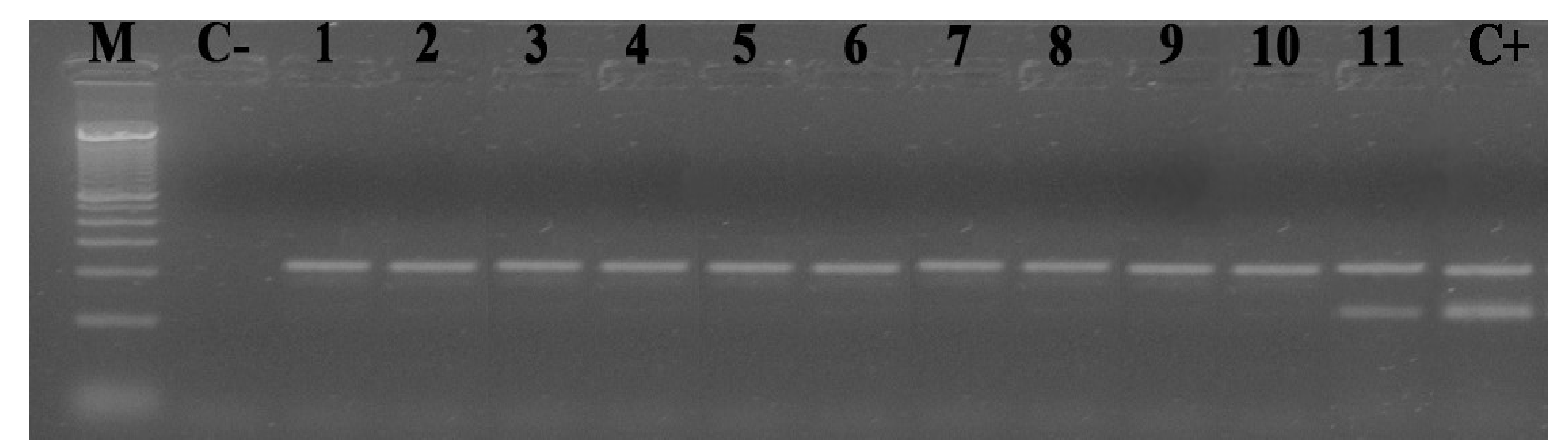

Fig. 4 - PCR result from tested Leishmania samples in $2 \%$ agarose gel electrophoresis. Lane M - Marker (1kb DNA ladder), Lane Cnegative control, Lanes 1 and 2- male Phlebotomus specimen; Lanes 3-10 - negative Phebotomus female, 11 - positive female for Leishmania, C+ reaction positive control

4. One specimen (3.5\%) of S. minuta (in a peridomestic biotope of Beja) was positive for L. infantum by molecular techniques. This is the first description of S. minuta infected with $L$. infantum in Portugal. This occurrence combined with previous report of Sergentomyia spp. infected with $L$. major and others species, supports the potential incrimination of this sand fly specie as Leishmania vector (Maia \& Depaquit, 2016). Furthermore, recently, human DNA was detected in engorged S. minuta in Algarve, Portugal (Maia et al, 2015).

5. In 2017, we will continue the sand fly captures in the same and other areas, intending to clarify these and others issues, once in $1999-2000$ none infected sand fly females was detected in Évora region (Alves-Pires et al, 2004).

References:

Alves-Pires C, Afonso MO, Janz JG, Semião-Santos SJ, 2004. The phlebotomine sand flies of Portugal. XII The phlebotomine of Evora leishmaniasis focus (1999-2000). Acta Parasitológica Portuguesa, 11: 41-45.

Campino L, Cortes S, Dionísio L, Neto L, Afonso MO, Maia C, 2013. The first detection of Leishmania major in naturally infected Sergentomyia minuta in Portugal. Mem Inst Oswaldo Cruz 108(4): 516-8.

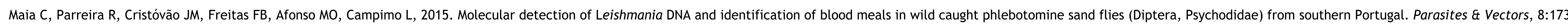
Maia C \& Depaquit J, 2016. Can Sergentomyia (Diptera, Psychodidae) play a role in the transmission of mammal-infecting Leishmania ? Parasite, 23, 55.

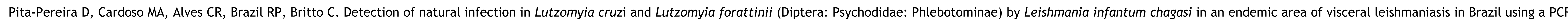
multiplex assay. Acta Trop 2008. 107(1):66-9. 